\title{
Cognitive impairment, retrospective and prospective memory, and visual inattention in chronotype
}

\author{
Związek chronotypu z upośledzeniem funkcji poznawczych: pamięci \\ retrospektywnej i prospektywnej oraz uwagi wzrokowej
}

\author{
Esfandiar Azad-Marzabadi¹, Sohrab Amiri², Sepideh Behnezhad³ \\ ${ }^{1}$ Baqiyatallah University of Medical Sciences, Behavioral Sciences Reasearch Center, Tehran, Iran \\ ¿Urmia University, Urmia, Iran \\ ${ }^{3}$ Kharazmi University, Tehran, Iran
}

Neuropsychiatria i Neuropsychologia 2017; 12, 2: 54-60

Address for correspondence:

Ph.D. Sohrab Amiri

Urmia University

Urmia, Iran

e-mail: amirysohrab@yahoo.com

\section{Abstract}

Aim of the study was to evaluate cognitive impairment, retrospective and prospective memory, and visual inattention in chronotype personality tendencies.

Methods: A total of 676 students of Bu Ali Sina University were selected in 2017. Subsequently, 150 of them were selected for the second stage according to the scores in the morningness-eveningness questionnaire (MEQ): as a morning person, an evening person, or intermediate. Finally, participants were studied in executive functions, memory function, and visual inattention.

Results: The results showed that there is a significant difference between the morningness-eveningness personality groups in executive functions, memory function, and visual inattention $(p<0.05)$. Participants with eveningness and intermediate personality had higher performance in retrospective memory, prospective memory, general memory, visual/spatial, naming, and attention. This difference was significant $(p<0.05)$. Also, participants with morningness and intermediate traits had higher performance in right and left visual attention $(p<0.05)$.

Conclusions: It can be concluded that morningness tendencies have worse cognitive performance in executive functions and eveningness tendencies have deficiencies in visual attention.

Key words: executive functions, morningness-eveningness, visual attention, retrospective and prospective memory.

\section{Introduction}

The concept of executive functions is derived from neuroscience, and it is widely used to describe the conscious functions as well as the processes involved in the control of the conscious thought, action, and emotion. These functions refer to the high-level of executive functions, which is linked to the brain's frontal lobe, including abilities such as planning, organising, problem-solving, working memory, and decision-making (Lezak et al. 2004). There are neural processes involved in the acquisition, processing, storage, and use of information (Shettleworth 2010), which were developed due to the need to solve ecological problems (Cnotka et al. 2008) and guide complex social environments, and they are also the interface between the behaviour and the structure of the brain (Hill et al. 2010). Therefore, the executive functions (EF) usually refer to processes used for self-regulation thoughts and goal-oriented behaviours (Alvarez and Emory 2006). One important factor for executive functions, which has received little attention, is biological dimensions of personality. In terms of psychiatric vulnerability, there is also a difference between these types, so that the evening types are more prone to depression and anxiety (Antypa et al. 2016).

The morningness-eveningness trait is known as a biological dimension of personality, which is largely the result of heredity (Adan et al. 2012). In addition to physiological differences between morningness-eveningness types (e.g. patterns of secretion of cortisol and melatonin), some psychological differences have been reported between these two types. For example, evening people have shown higher scores in extraversion (e.g. Díaz-Morales 2007; Matthews 1988) and 
novelty-seeking (Caci et al. 2004; Killgore 2007; Maestripieri 2014).

Circadian cycles are time swings in the physiological and behavioural functions that show approximately a 24-hour cycle. In humans, this cycle is regulated by a biological clock found in the suprachiasmatic nucleus of the hypothalamus, which regulates secretion of melatonin in the pineal gland (Piffer et al. 2014). There are individual differences in sleep-wake cycles and circadian time, so some people prefer to wake up early in the morning and go to bed early the night, while others prefer the opposite pattern (Aden et al. 2012). These differences in sleep patterns are associated with the difference in peak cognitive performance, so some people reach their peak performance in the morning while others have effective functioning in the late evening and at night (Preckel et al. 2011).

In addition to the physiological differences between the morning and evening people (daily patterns of melatonin and cortisol secretion) (Roberts and Kyllonen 1999), a broad range of research has been done on the psychological and personality correlates of morningness-eveningness types (Maestripieri 2014), and some research has been done on the relationship of these constructs with executive functions and intelligence (Nowack et al. 2014; Randler 2017; Panev et al. 2017). Executive functions are potentially sensitive to the effects of lack of sleep and the time of day, and lead to fluctuations in the cognition circadian cycle (Valdez et al. 2010); these differences may be related to the circadian cycle, so that there is a difference between morningness-eveningness peak-time of alertness and performance (Hahn et al. 2012).

For the first time, the relations between circadian cycles and cognitive function was expressed by Roberts and Kyllonen (1999), who showed that the eveningness orientation compared with the morningness type had a higher working memory and received higher scores on tasks related to memory and information processing speed. Similarly, some studies have stated that speed and accuracy in cognitive tasks, such as working memory, response inhibition, or tasks related to the reaction time, may be influenced by differences in the circadian cycle (Blatter and Cajochen 2007; García et al. 2012; Valdez et al. 2010; Wright et al. 2002). Considering the role of executive functions in many social and academic situations and the fact that there are few studies investigating the relationship between executive functions based on changes in the circadian cycle, the aim of this study was to investigate different aspects of executive functions, memory, and visual attention on the basis of individual differences in chronotype.

\section{Methods}

\section{Participants and procedure}

Due to not manipulating the variables and comparing the groups, this study belongs to descriptive post event researches (causal-comparative). The study participants comprised 676 students who were selected through multi-stage cluster sampling among university students. Inclusion criteria were: being aged 18 or older, and all participants reported that they had not been diagnosed with any medical condition (physical, but not necessarily psychological disorders) by a doctor. Participants with a psychotic disorder, problems with substance, acute suicidality, insufficient language skills, or severe cognitive impairment were excluded.

Participants completed morningness-eveningness questionnaires following an informed consent procedure and were provided with debriefing information on the purpose of the study and given a list of community counselling agencies at the end of the survey.

In accordance with the guidelines for the ethical treatment of human participants of the Iranian Psychological Association, all participants were informed fully about the aims of the research, and formal consent was obtained prior to commencing data collection. Then through cut-off score on morningness-eveningness questionnaires (score $>59$ $=$ morningness; score $<42=$ eveningness; score $>42$ and score $<59=$ intermediate) participants were categorised in three groups of morningness, eveningness, and intermediate tendencies. In the next step, the three groups' participants (each group consisted of 50 students) were invited to the Psychology Laboratory to measure cognitive impairment, retrospective and prospective memory, and visual inattention. Then the researcher explained the study's procedure to the participants of the three groups, who were finally studied for cognitive impairment, retrospective and prospective memory, and visual inattention. It should be mentioned that the participants of the second phase were studied individually. Missing data were excluded from the final sample and replaced by new participants. Of all the participants, 344 were female 
Table 1. The research participants' demographic characteristics $(n=150)$

\begin{tabular}{lccccc} 
Group & Gender & Number (percent) & \multicolumn{2}{c}{ Marital Status } & Age \\
& & & Single & (SD) \\
\cline { 3 - 6 } Morningness & & & Married & 4 & $21 / 00(0 / 75)$ \\
& Women & $15(30)$ & 11 & 31 & $19 / 77(1 / 83)$ \\
\hline Eveningness & Men & $35(70)$ & 8 & 0 & $20 / 50(0 / 53)$ \\
& Women & $8(16)$ & 38 & 4 & $20 / 38(1 / 83)$ \\
\hline Intermediate & Men & $42(84)$ & 6 & 0 & $21 / 66(2 / 16)$ \\
& Women & $6(12)$ & 38 & 6 & $20 / 16(1 / 76)$ \\
\hline
\end{tabular}

$(50.88 \%)$ and 333 were male $(49.12 \%)$. Respectively, the mean and standard deviation of the students' ages were 20.01 and 1.57 in males, and 21.97 and 1.66 in females. Demographic characteristics of participations in second stage are presented in Table 1.

\section{Measures}

\section{Morningness-Eveningness Questionnaire (MEQ)}

The MEQ is composed of 19 self-report items. This questionnaire's method of scoring is that some questions are dominated by 5-point, some 4-point, and some 6-point. Each item required individuals to denote the degree to which they agree with the definitions of morningness or eveningness. For example: "Assuming adequate environmental conditions, how easily do you get up in the morning?" $(1-$ not at all easily, 2 - not very easily, 3 - fairly easily, 4 - very easily) (Horn and Ostenberg 1976). A score higher than 59 indicates morningness type, lower than 42 indicates eveningness type, and between 42 and 59 indicates intermediate type.

\section{Bells Cancellation Test}

This test measures visual attention. The Bells Test (Gauthier et al. 1989) consists of a 21.5 $\times 28 \mathrm{~cm}$ sheet of paper on which seven lines of 35 distractor figures (e.g. bird, key, apple, mushroom, car) and five target figures (bells) are presented. The target figures are arranged so that five of them appear in seven equal columns on the page. The number of distractor figures in each column also remains constant.

\section{Retrospective and Prospective Memory Questionnaire}

This test is used to measure retrospective, prospective, and general memory. This questionnaire, with 16 items, contains three subscales of prospective memory, retrospective memory, and a general scale as general memory, which is obtained from subscales. The scoring of the questionnaire is based on the Likert scale in a high to low order $(5,4,3$, 2, 1). Crawford et al. (2003) reported that the reliability of the questionnaire is acceptable using internal consistency in a prospective, retrospective, and general subscale, and Cronbach's $\alpha$ coefficients of $0 / 80,0 / 84$, and $0 / 89$ have been reported for retrospective memory, prospective, and general scale, respectively (Crawford et al. 2003).

\section{Executive functions test}

This test is one of the tools for evaluating executive functions and attention. This test examines seven areas of cognition through various skills including visual-spatial, naming, orientation, attention, speech, abstraction, and memory (Nasreddine et al. 2005).

\section{Data analytic strategy}

SPSS version 22 (SPSS IBM, New York) was used to perform statistical analyses. The obtained data was analysed using descriptive indicators, multivariate analysis of variance, and Scheffe's post boc test.

\section{Results}

The mean and standard deviation of three personality group variables are listed in Table 2.

Multivariate analysis of variance was used to compare the groups with regard to cognitive impairment, retrospective and prospective memory, and visual inattention. The result of $M$ box test showed that the assumption of the dependent variables' variance-covariance's sameness of matrix was true and multivariate analysis of variance could be applied. The results of multivariate tests of Pillai, Wilks' lambda, Hetling, and Roy's Maximum Root are shown in Table 3. 
The data of Table 3 imply that there is a significant difference between the three groups, at least in one of the dimensions of cognitive impairment, retrospective and prospective memory, and visual inattention.

Considering the significance of group differences, one-way analysis of variance and Scheffe's post hoc test were used to determine in which groups and which levels of variables the differences are, and the results are shown in Table 4.

According to the results in Table 4, it can be said that the comparison of the three groups represented significant differences in some of the aspects of cognitive impairment, retrospective and prospective memory, and visual inattention; the participants with eveningness and intermediate traits had higher performance in retrospective memory, prospective memory, general memory, visual/spatial, naming, and attention. This difference was significant. Also, participants with morningness and intermediate traits had higher performance in right and left visual attention.

\section{Discussion}

Morningness and eveningness traits $(\mathrm{M} / \mathrm{E})$ are considered as personality dimensions (Matthews 1988); morningness or eveningness refer to individual differences in biological cycles such as sleep-wake and a time that a person feels best, and these differences are determined by several factors such as endogenous genetic factors that influence various psychological dimensions (Adan et al. 2012; Archer et al. 2003). Accordingly, the aim of this study was to investigate different aspects of executive functions, memory, and visual attention on the basis of individual differences in the morningness-eveningness circadian cycle.

The results of the study of cognitive aspects based on the comparison of morningness and eveningness types showed that participants with eveningness and intermediate traits had higher performance in retrospective memory, prospective memory, general memory, visual/ spatial, naming, and attention. This finding is consistent with the results of the study done by Roberts and Kyllonen (1999), who showed that eveningness types received higher scores on some cognitive tasks; and they are also consistent with the studies that expressed a positive relationship between eveningness circadian cycles and cognitive function and intelligence (Preckel et al. 2011). This finding also confirms the hypothesis of a link between circadian cycles and executive functions, and that eveningness 
Table 3. Multivariate analysis of variance of the groups' comparison in study variables

\begin{tabular}{lcccccc} 
Test's name & Value & $\begin{array}{c}\text { Hypothesis } \\
\text { DF }\end{array}$ & Error $\boldsymbol{D F}$ & $\boldsymbol{F}$ & Sig & $\eta^{2}$ \\
Pillai's trace & $0 / 49$ & 22 & 276 & $4 / 13$ & $0 / 001$ & $0 / 25$ \\
\hline Wilks' lambda & $0 / 54$ & 22 & 274 & $4 / 42$ & $0 / 001$ & $0 / 26$ \\
\hline Hetling's effect & $0 / 76$ & 22 & 272 & $4 / 70$ & $0 / 001$ & $0 / 28$ \\
\hline Roy's maximum root & $0 / 64$ & 11 & 138 & $8 / 10$ & $0 / 001$ & $0 / 39$ \\
\hline
\end{tabular}

Table 4. The results of the three groups' one-way analysis of variance and post hoc test

\begin{tabular}{|c|c|c|c|c|c|}
\hline Dependent variable & $F$ & Eta $\left(\eta^{2}\right)$ & Source of comparison & $\begin{array}{c}\text { Mean } \\
\text { differences }\end{array}$ & $\begin{array}{c}\text { Standard } \\
\text { error }\end{array}$ \\
\hline Retrospective memory & $8 / 01$ & $0 / 10$ & $\begin{array}{l}\text { Morningness-Eveningness } \\
\text { Morningness-Intermediate } \\
\text { Eveningness-Intermediate }\end{array}$ & $\begin{array}{c}-3 / 54^{* * *} \\
-1 / 48 \\
2 / 06\end{array}$ & $\begin{array}{l}0 / 88 \\
0 / 88 \\
0 / 88\end{array}$ \\
\hline Prospective memory & $11 / 37$ & $0 / 13$ & $\begin{array}{l}\text { Morningness-Eveningness } \\
\text { Morningness-Intermediate } \\
\text { Eveningness-Intermediate }\end{array}$ & $\begin{array}{c}-4 / 04^{\star * *} \\
-3 / 24^{\star *} \\
0 / 80\end{array}$ & $\begin{array}{l}089 \\
0 / 89 \\
0 / 89\end{array}$ \\
\hline General memory & $10 / 57$ & $0 / 13$ & $\begin{array}{c}\text { Morningness-Eveningness } \\
\text { Morningness-Intermediat } \\
\text { Eveningness-Intermedia }\end{array}$ & $\begin{array}{c}-7 / 58^{\star * \star} \\
-4 / 72^{\star} \\
2 / 86\end{array}$ & $\begin{array}{l}1 / 66 \\
1 / 66 \\
1 / 66\end{array}$ \\
\hline Visual/spatial & $8 / 45$ & $0 / 10$ & $\begin{array}{l}\text { Morningness-Eveningness } \\
\text { Morningness-Intermediate } \\
\text { Eveningness-Intermediate }\end{array}$ & $\begin{array}{c}-0 / 58^{\star * *} \\
-0 / 48^{* *} \\
0 / 10\end{array}$ & $\begin{array}{l}0 / 15 \\
0 / 15 \\
0 / 15\end{array}$ \\
\hline Naming & $3 / 57$ & $0 / 05$ & $\begin{array}{l}\text { Morningness-Eveningness } \\
\text { Morningness-Intermediate } \\
\text { Eveningness-Intermediate }\end{array}$ & $\begin{array}{c}-0 / 24^{*} \\
-0 / 18 \\
0 / 06\end{array}$ & $\begin{array}{l}0 / 09 \\
0 / 09 \\
0 / 09\end{array}$ \\
\hline Abstraction & $0 / 34$ & 0/01 & $\begin{array}{l}\text { Morningness-Eveningness } \\
\text { Morningness-Intermediate } \\
\text { Eveningness-Intermediate }\end{array}$ & $\begin{array}{l}0 / 06 \\
-0 / 04 \\
-0 / 10\end{array}$ & $\begin{array}{l}0 / 12 \\
0 / 12 \\
0 / 12\end{array}$ \\
\hline Memory & $2 / 92$ & $0 / 04$ & $\begin{array}{l}\text { Morningness-Eveningness } \\
\text { Morningness-Intermediate } \\
\text { Eveningness-Intermediate }\end{array}$ & $\begin{array}{c}0 / 60 \\
0 / 14 \\
-0 / 46\end{array}$ & $\begin{array}{l}0 / 25 \\
0 / 25 \\
0 / 25\end{array}$ \\
\hline Orientation & $0 / 83$ & 0/01 & $\begin{array}{l}\text { Morningness-Eveningness } \\
\text { Morningness-Intermediate } \\
\text { Eveningness-Intermediate }\end{array}$ & $\begin{array}{l}-0 / 10 \\
-0 / 18 \\
-0 / 08\end{array}$ & $\begin{array}{l}0 / 13 \\
0 / 13 \\
0 / 13\end{array}$ \\
\hline Attention & $5 / 74$ & 0/07 & $\begin{array}{l}\text { Morningness-Eveningness } \\
\text { Morningness-Intermediate } \\
\text { Eveningness-Intermediate }\end{array}$ & $\begin{array}{c}-0 / 36^{\star} \\
0 / 02 \\
0 / 38^{\star}\end{array}$ & $\begin{array}{l}0 / 12 \\
0 / 12 \\
0 / 12\end{array}$ \\
\hline Speech & $1 / 29$ & $0 / 02$ & $\begin{array}{l}\text { Morningness-Eveningness } \\
\text { Morningness-Intermediate } \\
\text { Eveningness-Intermediate }\end{array}$ & $\begin{array}{c}0 / 20 \\
0 / 16 \\
-0 / 04\end{array}$ & $\begin{array}{l}0 / 13 \\
0 / 13 \\
0 / 13\end{array}$ \\
\hline Left visual attention & $3 / 62$ & $0 / 05$ & $\begin{array}{l}\text { Morningness-Eveningness } \\
\text { Morningness-Intermediate } \\
\text { Eveningness-Intermediate }\end{array}$ & $\begin{array}{c}0 / 16 \\
-0 / 04 \\
-0 / 20^{\star}\end{array}$ & $\begin{array}{l}0 / 07 \\
0 / 07 \\
0 / 07\end{array}$ \\
\hline Right visual attention & $14 / 85$ & $0 / 17$ & $\begin{array}{l}\text { Morningness-Eveningness } \\
\text { Morningness-Intermediate } \\
\text { Eveningness-Intermediate }\end{array}$ & $\begin{array}{c}0 / 64^{* * *} \\
0 / 16 \\
-0 / 48^{* * *}\end{array}$ & $\begin{array}{l}0 / 12 \\
0 / 12 \\
0 / 12\end{array}$ \\
\hline Centre visual attention & $0 / 00$ & $0 / 00$ & $\begin{array}{l}\text { Morningness-Eveningness } \\
\text { Morningness-Intermediate } \\
\text { Eveningness-Intermediate }\end{array}$ & $\begin{array}{l}- \\
- \\
-\end{array}$ & $\begin{array}{l}- \\
- \\
-\end{array}$ \\
\hline
\end{tabular}

${ }^{* * *}=p<0.001,{ }^{* *}=p<0.01,{ }^{*}=p<0.05$

orientation has higher scores on intelligence of eveningness in academic performance in and executive functions (Piffer et al. 2014). high-school students. Given that intelligence Also, this study is in line with Preckel et al. as a pervasive component includes many ex(2013), who showed a negative predictive role ecutive functions, the present study indicates 
a relationship between eveningness type and some cognitive dimensions, which is consistent with the study of Preckel et al. (2011).

Participants with morningness and intermediate traits had higher performance in right and left visual attention as well. These findings suggest that morningness and eveningness types are superior in some cognitive tasks. The findings may be explainable using the hypothesis that different brain structures have been organised for specific assignments, thus each of these structures possibly shows a better performance under environmental conditions and in particular circadian cycles, and thus have enabled humans in evolution to have better compatibility. A variety of explanations have been mentioned to describe the differences between morningness-eveningness types in executive functions. According to the hypothesis of educational effects, eveningness types have a greater need to overcome their daily problems caused by the conflict with social requirements, and this need can actually lead to higher scores on cognitive dimensions (Preckel et al. 2011). A second explanation suggests that the relationship between eveningness type and higher executive functions is caused due to the fact that eveningness types sleep less in comparison with the morningness types, and regardless of circadian type, more intelligent people tend to sleep less, and the result is that during the night better neurological recovery happens (Geiger $e t$ al. 2010). Finally, it is stated that the eveningness types may have evolved through sexual selection because activity late at night provides more time to reproduce a baby in a short time (Piffer 2010). From this perspective, higher intelligence in the eveningness types may be linked with intelligence of their sex couples (Miller 2001; Geher and Kaufman 2013).

Another explanation for the above findings has been provided: cyclical fluctuations in executive functions may reflect differences in sleepwake times, which is associated with the wakeup time and the difference in circulation cycles (Schmidt and Collette 2007). In other words, the hypothesis states that the daily fluctuations in executive functions can reflect the cycles of general arousal patterns. However, this hypothesis cannot fully be confirmed because the data show that the rhythm of cognitive function cannot be the result of cyclical changes in the indicators of physiology (Blatter et al. 2005; Frey et al. 2004).

In general, the results showed that the performance in executive function tasks is influenced by individual differences in morn- ingness-eveningness circadian cycles. There are several limitations of the current study. First, participants' reports were obtained retrospectively. Therefore, recall bias could impact participants' self-reporting. So, according to what was said, the present study was conducted among student population samples, and since it did not cover all other groups, the results should be treated with caution in generalising. In conclusion, the current study provides empirical support for the role of circadian cycles in executive functions. This is the first known study to examine these relationships, and more studies are needed to more fully understand the underlying mechanisms.

\section{Ethical approval}

All procedures performed in studies involving human participants were in accordance with the ethical standards of the institutional and/or national research committee and with the 1964 Helsinki Declaration and its later amendments or comparable ethical standards.

\section{Informed consent}

Informed consent was obtained from all individual participants included in the study.

\section{Acknowledgements}

The authors assert that ethical approval for publication of this study has been provided by their local REC. The authors declare that they have no conflicts of interest and that this study received no funding.

\section{References}

1. Adan A, Archer SN, Hidalgo MP, et al. Circadian typology: A comprehensive review. Chronobiol Int 2012; 29: 11531175.

2. Alvarez JA, Emory E. Executive function and the frontal lobes: a meta-analytic review. Neuropsychol Rev 2006; 16: $17-42$.

3. Antypa N, Vogelzangs N, Meesters Y, et al. Chronotype associations with depression and anxiety disorders in a large cohort study. Depress Anxiety 2016; 33: 75-83.

4. Archer SN, Robilliard DL, Skene DJ, et al. A length polymorphism in the circadian clock gene Per3 is linked to delayed sleep phase syndrome and extreme diurnal preference. Sleep 2003; 26: 413-415.

5. Biancardi A, Stoppa E. Il test delle Campanelle modificato: Una proposta per lo studio dell'attenzione in eta evolutiva. Psichiatria dell'infancia e dell'adolescenza 1997; 64: 73-84.

6. Blatter K, Cajochen C. Circadian rhythms in cognitive performance: methodological constraints, protocols, theoretical underpinnings. Physiol Behav 2007; 90: 196-208. 
7. Blatter K, Opwis K, Munch M, et al. Sleep loss-related decrements in planning performance in healthy elderly depend on task difficulty. J Sleep Res 2005; 14: 409-417.

8. Caci H, Robert P, Boyer P. Novelty seekers and impulsive subjects are low in morningness. Eur Psychiatry 2004; 19: 79-84.

9. Cnotka J, Güntürkün O, Rehkämper G, et al. Extraordinary large brains in tool-using New Caledonian crows (Corvus mon-eduloides). Neurosci Lett 2008; 433: 241e245.

10. Crawford JR, Smith G, Maylor E, et al. The Prospective and Retrospective Memory Questionnaire (PRMQ): Normative data and latent structure in a large non-clinical sample. Memory 2003; 11: 261-275.

11. Díaz-Morales JF. Morning and evening-types: Exploring their personality styles. Pers Individ Dif 2007; 43: 769-778.

12. Frey DJ, Badia P, Wright KPJ. Interand intra-individual variability in performance near the circadian nadir during sleep deprivation. J Sleep Res 2004; 13: 305-315.

13. García A, Ramírez C, Martínez B, Valdez P. Circadian rhy thms in two components of executive functions: cognitive inhibition and flexibility. Biological Rhythm Research 2012; 4: 49-63.

14. Gauthier L, DeHaut F, Joanette Y. The Bells Test: A quantitative and qualitative test for visual neglect. Int J Clin Neuropsychol 1989; 11: 49-54.

15. Geher G, Kaufman SB. Mating intelligence unleashed: The role of the mind in sex, dating and love. Oxford University Press, Oxford 2013.

16. Geiger A, Achermann P, Oskar G. Association between sleep duration and intelligence scores in healthy children. Dev Psychol 2010; 46: 949-954.

17. Hahn C, Cowell JM, Wiprzycka UJ, et al. Circadian rhythms in executive function during the transition to adolescence: the effect of synchrony between chronotype and time of day. Dev sci 2012; 15: 408-416.

18. Hill B, Elliott EM, Shelton JT, et al. Can we improve the clinical assessment of working memory? An evaluation of the Wechsler Adult Intelligence Scale-Third Edition using a working memory criterion construct. J Clin Exp Neuropsychol 2010; 32: 315-323.

19. Horn JA, Ostenberg OA. Self-assesment questionnaire to determine morningnesseveningness in human circadian rhythms, Int J Chronobiol 1976; 74: 97-110.

20. Killgore WDS. Effects of sleep-deprivation and morningness-eveningness traits on risk-taking. Psychol Rep 2007; 100: 613-626.

21. Laurent-Vannier A, Pradat-Diehl P, Chevignard M. Negligence spatiale unilaterale et motrice chez l'enfant. Revue Neurologique 2001; 157: 414-422.

22. Lezak MD, Howieson DB, Loring DW, et al. Neuropsychological assessment $\left(4^{\text {th }}\right.$ ed). Oxford University Press, New York 2004.

23. Maestripieri D. Night owl women are similar to men in their relationship orientation, risk-taking propensities, and cortisol levels: Implications for the adaptive significance and evolution of eveningness. Evol Psychol 2014; 12: 130-147.

24. Matthews G. Morningness-eveningness as a dimension of personality: Trait, state and psychophysiological correlates. Eur J Pers 1988; 2: 277-293.

25. Miller G. The mating mind: How sexual choice shaped the evolution of human nature. Anchor, New York 2001.

26. Nasreddine ZS, Phillips NA, Bedirian V, et al. The Montreal Cognitive Assessment, MoCA: a brief screening tool for mild cognitive impairment. J Am Geriatr Soc 2005; 53: 695-699.
27. Nowack K, van der Meer E. Impact of chronotype and time perspective on the processing of scripts. Int I Psychophysiol 2014; 92: 49-58.

28. Panev AS, Tserne TA, Polugrudov AS, et al. Association of chronotype and social jetlag with human non-verbal intelligence. Chronobiol Int 2017; 24: 1-4.

29. Piffer D. Sleep patterns and sexual selection: An evolutionary approach. Mankind Q 2010; 50: 361-375.

30. Piffer D, Ponzi D, Sapienza P, et al. Morningness-evenin gness and intelligence among high-achieving US stu dents: Night owls have higher GMAT scores than early morning types in a top-ranked MBA program. Intelligence 2014; 47: 107-112

31. Preckel F, Lipnevich AA, Schneider S, Roberts RD. Chronotype, executive functions, and academic achievement: A meta-analytic investigation. Learn Individ Differ 2011; 21: 483-492.

32. Preckel F, Lipnevich AA, Boehme K, et al. Morningness -eveningness and educational outcomes: the lark has an advantage over the owl at high school. Br J Educ Psychol 2013; 83: 114-134.

33. Randler C. Chronotype correlates with developmental index, intelligence and academic achievement: A study based on nationwide indicators. Chronobiol Int 2017; 8: 1-8.

34. Roberts RD, Kyllonen PC. Morningness-eveningness and intelligence: Early to bed, early to rise will make you anything but wise! Pers Individ Dif 1999; 27: 1123-1133.

35. Schmidt C, Collette F. A time to think: Circadian rhythms in human cognition. Cog Neuropsychol 2007; 24: 755-789.

36. Shettleworth SJ. Cognition, Evolution, and Behavio ( $2^{\text {nd }}$ ed). Oxford University Press, New York 2010.

37. Valdez P, Ramirez C, Garcia A, et al. Circadian and homeostatic variation in sustained attention. Chronobiol Int 2010; 27: 393-416.

38. Wright KP, Hull JT, Czeisler CA. Relationship between alertness, performance, and body temperature in humans. Am J Physiol Regul Integr Comp Physiol 2002; 283: 1370-1377. 